NASA Technical Memorandum 87191

\title{
In-Flight Photogrammetric Measurement of Wing Ice Accretions
}

(HASA-TA-87191). IN-FLIGHT PHOTOGRAMAETRIC MEASUREMENT OF WING ICE ACCRETIONS (NASA) $14 \mathrm{p}$

CSCL $01 C$

N86-31562

Unclas

$63 / 05 \quad 430-95$

Robert C. McKnight

Lewis Research Center

Cleveland, Ohio

and

Richard L. Palko and Robert L. Humes

Calspan Corporation

Arnold Air Force Station, Tennessee

Prepared for the

Twenty-fourth Aerospace Sciences Meeting sponsored by the American Institute of Aeromautics and Astronautics Reno, Nevada, January 6-8, 1986

\section{N/Sก}




\title{
IN-FLIGHT PHOTOGRAMMETRIC MEASUREMENT OF WING. ICE ACCRETIONS
}

\author{
Robert C. Mcknight \\ National Aeronautics and Space Administration \\ Lewis Research Center \\ Cleveland, Ohio 44135
}

and

Richard L. Palko and Robert L. Humes

Calspan Corporation

Arnold Air Force Station, Tennessee

\section{SUMMARY}

A photographic instrumentation system was developed for the Lewis icing research aircraft to measure wing ice accretions during flight. The system generates stereo photographs of the accretions which are then photogrammetrically measured by the Arnold Engineering and Development Center. The measurements yield a survey of spatial coordinates of an accretion's surface to an accuracy of at least $\pm 0.08 \mathrm{~cm}$. The accretions can then be matched to corresponding icing cloud and aerodynamic measurements. The system is being used to measure rime, mixed, and clear natural ice accretions.

\section{INTROOUCTION}

For several years, NASA Lewis Research Center has been conducting a natural icing flight research program with a DeHavilland DHC-6 Twin 0tter. Two of the program's elements are to record icing cloud parameters and iced aircraft drag changes (refs. 1 and 2). To help associate the cloud and drag data, measurement of wing ice accretion size and shape was needed. Stareo photogrammetry (ref. 3) was chosen to make this measurement for several reasons. First, the photographic data can be taken in. flight simultaneously with aerodynamic data so that ice accretions can be related to the aircraft's changes in aerodynamics without estimating losses from sublimation. The method does not distort the accretion process at the measurement area. The photographic equipment requirements appeared to be adaptable to the geometry and operating environment of the aircraft. Finally, the Air Force Arnold Engineering and Development Center (AEDC) had previously developed wind tunnel stereo photogrammetry systems which could be used as a basis for designing and developing an aircraft system. The AEDC wind tunnel: system uses high-convergence, closerange stereo photography along with an analytical compiler to measure aero-: elastic deflections and artificial ice accretions - measurements similar to those required for the aircraft system (refs. 4 and 5 ).

Lewis personnel, with AEDC's assistance, designed and developed the aircraft photography system. Lewis flight researchers took the photographic pairs during the Twin otter's fights in natural icing conditions. AEOC personne 1 performed the photograminetric measurements and calculations to produce each accretion's dimensional analysis. Lewis researchers then matched various flight accretions to icing cloud properties and drag measurements (ref. 1 ). 
The stereo system has been developed to the point where detailed measurement surveys of ice on the aircraft's wing can be routinely made to a spot measurement accuracy of $\pm 0.08 \mathrm{~cm}( \pm 0.03 \mathrm{in}$.$) . This accuracy is primarily$ made possible by the high resolution of the images, the accuracy and coverage of position reference control points in the images, and the corrections made for film distortion and wing flex during dimensional analysis.

During the last two icing seasons, 33 measurement surveys from nine flights were made to that accuracy from stereo photographs of rime, mixed, and clear ice accretions. The $X-Y-Z$ measurements of each survey were then used to form a two-dimensional plot of the accretion surface points projected onto the wing's cross section to depict the three-dimensional shape and roughness of the accretion (figs. 4 to 6 ).

The development of the system required the expert assistance of many individuals, among them Mr. Patrick L. Cassady of the AEDC Instrumentation Branch.

\section{APPROACH}

\section{Aircraft Stereo Photography Systems}

To ensure that the ice measurement resolution was acceptable for research use, a goal was set for a measurement accuracy of \pm 0.04 percent of the wing's $2-m(6-1 / 2-f t)$ chord.

Flight test limitations. - In designing a stereo photography system; several limitations had to be addressed related to applying this method to aircraft.flight test in natural icing conditions.

(1) There are few locations on the aircraft where it is feasible to install two cameras so that they have acceptable view angles and fields of view of the wing. Those locations are far from the wing section, and the space available at each is too small for many large-format cameras.

(2) The cameras have to operate in a low-temperature, vibrating enviranment.

(3) For making spatial measurements from stereo photographs, control points of known spatial positions must appear in each photograph. For very high accuracy the points should surround the area being measured. In wind tunne 1 and studio stereo photography, numerous surfaces for control points are usually avallable or can be added so that the points will surround or nearly surround the measurement area. However, for this flight test application the location for control points were very. limited since only the wing surfaces were available.

(4) Wing flex in relation to the fixed cameras shifts the position of the ice accretion in the cameras, views.

(5) Lewis' icing flights are limited to daylight hours. Thus, there is limited control of the intensity and direction of the ambient light in the photographs. Also, the ice accretions are typically low contrast surfaces. Photographs taken under most day lighting conditions will not record much of 
the surface detail of the ice unless shadowing from artificial lighting is added.

Cameras. - The locations selected for the two cameras are the nose radome and an equipment bay just forward of the cockpit (figs.l and 2). Hasselblad $70-\mathrm{mm}$ format cameras - a compromise between large format and compact size were used. The cameras are motor driven with a control system operated from the cockpit.

For increased image resolution, 250-mm telephoto lenses are used. To further increase the resolution, the cameras were modified with vacuum platens, as had been done in the AEDC stereo camera system (ref. 4). The platens hold the film flat in the camera's focal plane thereby minimizing focus variation across the image.

The cameras are also modified with the addition of fiducial marks. The marks were created by notching the structure that frames the film during exposure so that they appear on the perimeter of the photographs. AEDC uses the fiducial marks as a reference during their analysis since the marks are fixed at known positions in the view of the camera.

Control points. - The control points, reference marks of known spatial position relative to each other, were painted onto the leading edge of the wing in front of the wake survey probe (fig. 3 ). Since the leading edge is covered with a rubber de-icer boot, a rubber-based elastic paint (B.F. Goodrich Radalon) was used. The points were centered along the junctions of the boot's inflation tubes so that there was no possibility that their position might shift. For best dimensional analysis accuracy, the control point array should spatially surround the surface being measured. Therefore, control points were also painted on the wing fence to partially surround the ice without adding more structure to the wing.

The spatial position of each control point relative to the wing was then measured to within $0.02 \mathrm{~cm}( \pm 0.010 \mathrm{in}$.$) by AEOC personnel with their digital$ theodolite system (ref. 4). The high accuracy is required since the controlpoint tolerances limit the photogrammetric measurement accuracy. AEOC stored the measurements for later use with the ice accretion dimensional analysis.

Ninety-one points were applied to the boot and fence, encompassing a $1.2-m$ $(4-\mathrm{ft})$ span of the wing in front of the wake survey probe. Thirty-five of the points are used for the stereo analys is with the remainder being backup points.

Camera heating system. - To ensure that the cameras will operate properly in the low temperatures encountered during icing flights, each camera has a box mounted over it that is lined with electric heating pads.

These heaters maintain the camera temperatures at 75 to $100^{\circ} \mathrm{F}$. Also, 80 to $100^{\circ} \mathrm{F}$ air is blown over the inside surface of the forward viewport glass to keep it clear of fog and ice and over the camera lens to keep it defogged.

Camera operating parameters. - The cameras must operate at a fairly fast shutter speed of $1 / 125$ to $1 / 250 \mathrm{sec}$ to eliminate biur due to aircraft vibration. ASA $64 \mathrm{film}$ is used for all the photographs with the resulting aperature setting at $1 / 125 \mathrm{sec}$ being $f / 16$ and at $1 / 250 \mathrm{sec}, \mathrm{f} / 11$. 
Film. - Ektachrome 64 positive color film was used. Its fine-grain structure yields high-resolution images under high magnification. Also, subtle differences in the coloring of the ice surfaces produce more image contrast than would appear with black and white film.

Flash system. - To increase the contrast of the ice surface imagery and, thereby increase the visibie detail of the ice, a flash head is located to the side of the measurement area on the engine nacelle. It sidelights the rough ice surface to create brightness contrast in combination with the ambient daylight.

The high power output flash, a $2000-W$ sec unit, is necessary to produce lighting significantly brighter than the approximately $86 \times 10^{3} 1 \times(8000 \mathrm{fc})$ of daylight ambient lighting of bright in-flight conditions. The power unit for the flash is located in the aircraft's aft passenger cabin with the power leads being run through the right wing and engine nacelle.

Camera control system. - So that the cameras and flash can be operated from the cockpit, Lewis personnel designed and fabricated a camera control system. The system activates the camera shutters and the flash in synchronization. It also releases the vacuum on the film platens, advances the film, and reapplies the vacuum.

The camera and flash activation is initiated by pushing a button on the cockpit instrument panel. Only one camera shutter is synchronized with the flash at a time because of camera limitations. A switch on the instrument panel is used to transfer flash synchronization between shutters.

\section{Stereo Analysis System}

General background. - Stereo photogrammetry is a method of measuring the difference in a point's position as it appears in two images taken from known camera locations and from that difference calculating the spatial position of the point. The method has been traditionally used to create topographical maps from aerial photographs and more recently used for noncontact measurement of objects through close-range stereo photographs.

AEDC system. - AEDC personnel used an $H$. Del Foster DSC $3 / 80$ analytical complier to measure the photographs and calculate the spatial positions (ref. 4). The compiler consists of a photograph viewing and mensuration system coupled to an internal processing computer for the analys is and a mainframe computer for data manipulation and output. To increase measurement resolution, the photographs were individually magnified by the viewing system to a nominal 20x. Total magnification, when combined with that of the camera lenses, is about $50 x$.

The compiler system is used first to compensate for film distortion and wing flex and then to calculate the spatial positions of designated accretion surface points in the photographic pairs. The measurements are normally transferred to magnetic tape and hard copy printouts. 


\section{DATA ACQUISITION}

\section{In-Flight Photography}

In the usual routine for icing flights, the aircraft was flown in icing conditions while the icing cloud properties were measured and the ice accretion was allowed to build. Once the accretion reached the desired level, the aircraft was maneuvered clear of the clouds. Normally, only a short climb or descent was needed to get out of the cloud layer. Immediately after exiting the cloud, stereo photographs were taken before sublimation significantly distorted the accretion. Accretion dimensions from these photographs can be related to the icing cloud measurements. Flight in clear air was usually continued in order to perform aerodynamic measurements related to the accreted ice, such as wake survey sweeps. Photographs were taken simultaneously with those measurements as the accretion sublimated.

For taking each photographic pair, the aircraft was headed so that the Sun was in about a 6 to $80^{\prime}$ clock position to the fuselage to further enhance the sidelighting contrast across the surface of the ice. The camera shutter to which the flash was synchronized was then selected with a cockpit switch, and the cameras and flash were triggered with a cockpit button. After waiting $15 \mathrm{sec}$ for the flash power supply to recharge, the flash synchronization was switched to the other shutter, and the cameras and flash were triggered again

\section{Stereo Analysis}

Once a photographic pair was secured in the viewing and mensuration stages of the compiler, two routines were run to compensate for any film distortion from the photographic processing and for flexing of the wing. First, the positions of the fiducial marks as they appear on the photo were compared with the true positions of the marks in the camera frame, which are stored in the processing computer. Through several iterations of a statistical error analysis routine, film distortion adjustments for the control point and ice surface measurements were calculated and stored.

Second, the spatial coordinates of the control points measured from the photographs were compared with the points' known spatial positions as had been measured with the aircraft at rest. Through several iterations of another statistical error analysis routine, the camera-to-subject geometry for the stereo calculations was adjusted to account for wing flex in relation to the fixed views of the cameras. The geometry parameters were then stored for later computation of the ice accretion dimensions.

Each error analysis routine calculated an error index for each iteration. Through successive iterations, the error index was reduced below a predetermined value or the photo data was considered faulty.

The compiler operator then measured the image positions of ice accretion surface points and had the computer calculate their spatial positions. The operator selected points that were representative peaks and depressions on the ice surface so that their positions could be summed into a depiction of both the shape and roughness of the ice. Normally, about 200 points on the accretion surface were measured, and their spatial positions were recorded on magnetic tape and printouts as tables of $X-Y-Z$ coordinates. The matrix of 
points encompassed the chordwise extent of the ice surface in an approximately $0.46 \mathrm{~m}(1-1 / 2-\mathrm{ft})$ spanwise band in front of the wake survey probe.

\section{DATA REDUCTION}

To visualize each accretion, about 50 to 100 selected accretion surface points are plotted over a profile of the wing section (figs. 4 to 6 ). (The Twin otter wing has a constant cross section and angle of incidence:) The plot is a composite profile of the ice in that the points shown in the $X-Y$ plane lie along the $Z$ axis through the plane. The variation of the points is a measure of the accretion's roughness. Additionally, a line is drawn through the approximate mean of the points to produce a representative accretion profile.

\section{RESULTS AND DISCUSSION}

After a period of development, it became possible to rellably generate photographic pairs of ice accretions that could be measured to with in the $0.08 \mathrm{~cm}(0.03$ in.) goal. To date 33 photographic pairs of rime, mixed, and clear ice have been surveyed to that tolerance. Examples are shown in figures 4 to 6.

\section{Photo Image Generation}

$\therefore$ The optical qualities of the ice have a significant effect on the measurement surveys. Rime ice, with its opaque granular surface, is the easiest to measure. However, the mixed and clear types of accretions have central portions of translucent ice. Sometimes only cracks and bubbles below the indefinite surface are visible enough for accurate measurement (fig. 6). However, the opaque areas to either side of the central portion can be accurately measured.

Sidelighting from a flash unit was necessary even in the daylight photo-graphic conditions. Photographs taken without the flash displayed little light contrast on the ice surface, and details were hidden. Also, positioning the aircraft for as much solar sidelighting as possible improved image contrast.

Stereo photography in the icing clouds was unsuccessful. Backscattering of the light from the flash by the cloud droplets produced unusable imagery. Only in very thin clouds would the backscattering be negligible.

Each photograph of a stereo pair was taken individually during separate flash illuminations rather than simultaneously during a single flash. This was done, in part, because of the fast shutter speeds (1/125 to 1/250 sec) required to eliminate image motion caused by aircraft vibration. The linkage in each camera allowed small time variations between triggering and shutter response. These time variations become significant at the very short exposures. The flash was synchronized to one of the shutters (when the shutter was full open, it closed a contact to discharge the flash). If both cameras are triggered, the shutter of the unsynchronized camera cannot be depended upon to be open during the flash. Without matched light contrast in both photographs of the pair, precise stereo analysis is extremely difficult. As 
an alternative, the camera control system was modified so that the flash synchronization could be transferred between cameras. In this way, the flash discharge was synchronized to one of the shutters for the first set of exposures, then transferred to the other shutter for the second set of exposures. Using the exposures that were synchronized with the flash from each set produced photographic pairs with the required matched lighting. The time between the exposures was normally the 10 to $15 \mathrm{sec}$ needed for the flash power supply to recharge. Movement of the wing between exposures significant enough to affect the analysis was detected by the control point error analysis routine at the beginning of the measurement process. Error analysis results indicate this method of transferring synchronization has nearly always produced image pairs where the wing position has not changed between shots.

Color film is necessary to obtain the required resolution. Even though the ice surface appears basically white, fine color differences evident under. magnification increase the contrast and character of the surface so that more detail is apparent.

Dimensional Analysis

When the accretion has extreme feathering such as in figure 6 , the view of depressions between feathers may be blocked or heavily shadowed by adjacent feathers. In this case some of the deeper portions of the depressions may not be visible for measurement.

A more systematic process needs to be developed for selecting points to be measured and for data reduction. The compiler operator measured peaks and depressions in a local area that were, in his judgement, representative of the maximum and minimum thickness he was viewing. values from each local area were then assembled into a survey of about 200 points of the larger $0.46-m$ $(1-1 / 2-f t)$ span area. However, with the great variability that can occur across the accretion surface, there is little control over biasing the data. Further, the data reduction process should be developed for yielding mathematical expressions of the ice shape and roughness for use in analytical accretion codes, aerodynamic analysis, and fabrication of simulated ice shapes.

\section{Potential Research Applications}

There are a number of applications for in-flight measurements of wing ice accretions along with icing cloud and aerodynamic measurements.

(1) The method can be applied to correlate the ice accretions from icing simulation facilities (e.g., tunneis and icing tankers) with those from natural conditions.

(2) The natural accretion measurements can be used for constructing simulated ice that more realistically corresponds to particular icing cloud and aerodynamic conditions. In this way wind tunnel tests and flight tests in clear air with simulated ice may have closer correlation to natural conditions.

(3) The natural ice measurements can be used for refining and validating analytical models of the accretion process. 
(4) With more development, the method can possibly be extended to measuring helicopter blade accretions during forward flight (ref. 6)

\section{CONCLUSION}

The Lewis/AEDC stereo photogrammetry system demonstrates that detalled, accurate measurements of rime, mixed, and clear ice accretions on remote, flexing portions of an aircraft can be made in flight. In this way the accretion can be related to aerodynamic and icing cloud measurements. Also, sublimation of the ice accretion with time is documented.

The major constraints of the system are

1. The surface around the measurement area must be marked with control points so that the points will appear in the photographs. Preferabiy, the points should surround the area of interest.

2. To obtain sufficient detail in the imagery for high-resolution measurements, the ice surface contrast from natural lighting must be enhanced with supplemental side lighting.

3. The system cannot produce suitable imagery for high-resolution analysis while flying in clouds. For acceptable results photographs must be taken after the aircraft exits the icing cloud or enters an area of thin clouds.

In-flight stereo photogrammetry can be useful for correlating natural icing to tunnel and tanker icing and refining ice accretion predictive models. Also, it can be useful for constructing more realistic simulated ice accretions for wind tunnel tests and flight tests in clear air.

\section{CONCLUDING REMARKS}

Future efforts of this research will tackle the following tasks:

More systematic methods of surveying the accretions and reducing the data will be developed. The objective is to produce depictions and mathematical expressions of the accretion shape and roughness that have increased research utility.

The in-flight natural accretion measurements can be used, along with other data, to validate the artificial icing characteristics of NASA's Icing Research Tunnel.

The stereo photogrammetry method can be extended to measuring empennage accretions of Lewis' Twin otter icing research alrcraft. The data are used. for relating the accretions to iced aircraft stability and control measurements.

The data, along with cloud measurements, can be used for correlation with analytical ice accretion codes. The effort would produce codes with increased realism. 
Fabrication of simulated ice shapes for clear air flight tests can be done from the stereo data. The data should yield fice shapes that will produce aerodynamic changes more representative of natural icing.

\section{REFERENCES}

1. Mikkelsen, Kevin, L.; et al.: Icing Flight Research: Aerodynamic Effects of Ice and Ice Shape Documentation with Stereo Photography. NASA TM-86906, 1985.

2. Ranaudo, Richard L.; et al.: Performance Degradation of a Typical Twin Engine Commuter Type Aircraft in Measured Natural Icing Conditions. NASA TM-83564, 1984.

3. Slamp, C.C.; Theuver; C.; and Henriksen, S.W.; eds.: Manual of Photogrammetry, 4th ed., American Society of Photogrammetry, Falls Church, Virginia, 1980.

4. Palko, R.L.; and Cassady, P.L.: Photogrammetric Development and Application at AEDC. AIAA Paper 82-0610, 1982.

5. Palko, R.L.; and Cassady, P.L.: Photogrammetric Analysis of Ice Build-up on a U.S. Army UH-1H Helicopter Main Rotor in Hover Flight. AEDC TR $83-43$, Oct. 1983.

6. Palko, R.L.; et al.: Initial Feasibility Ground Test of a Proposed Photogrammetric System for Measuring the Shapes of Ice Accretions on Helicopter Rotor Blades During Forward Flight. AEDC TR 84-10, 1984. 


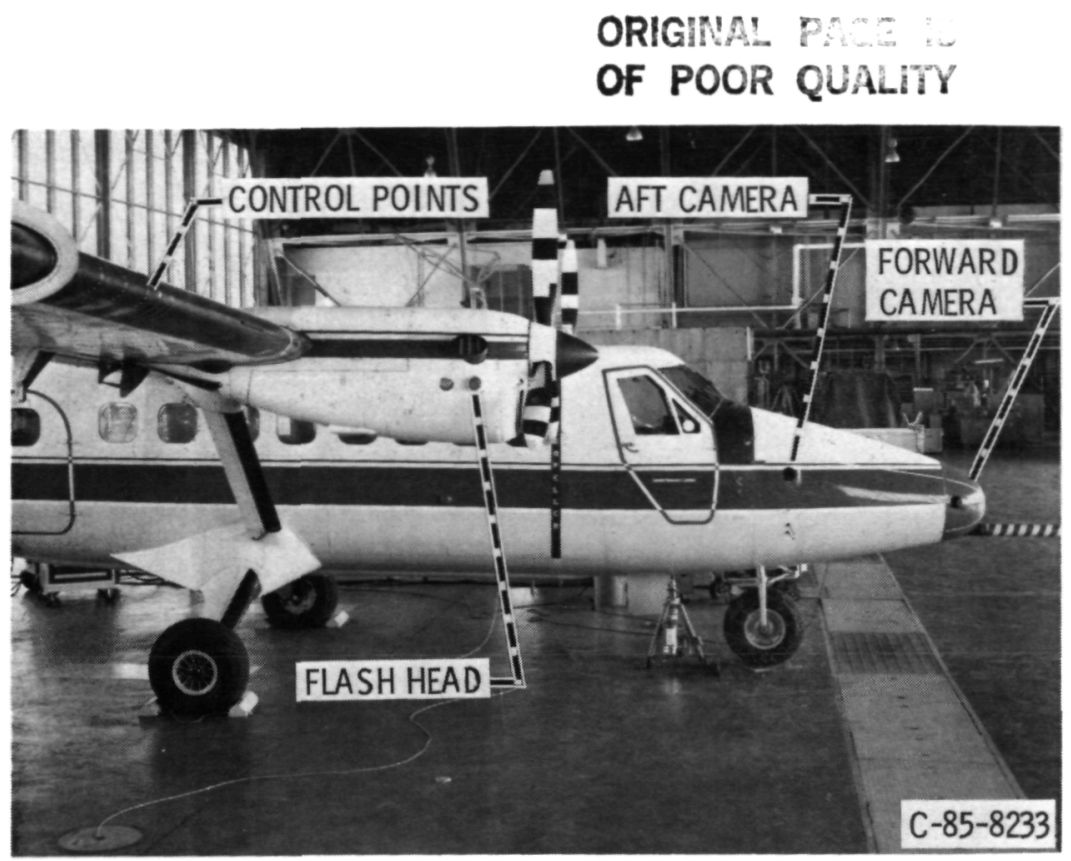

Figure l. - Twin Otter wing stereo photography system.
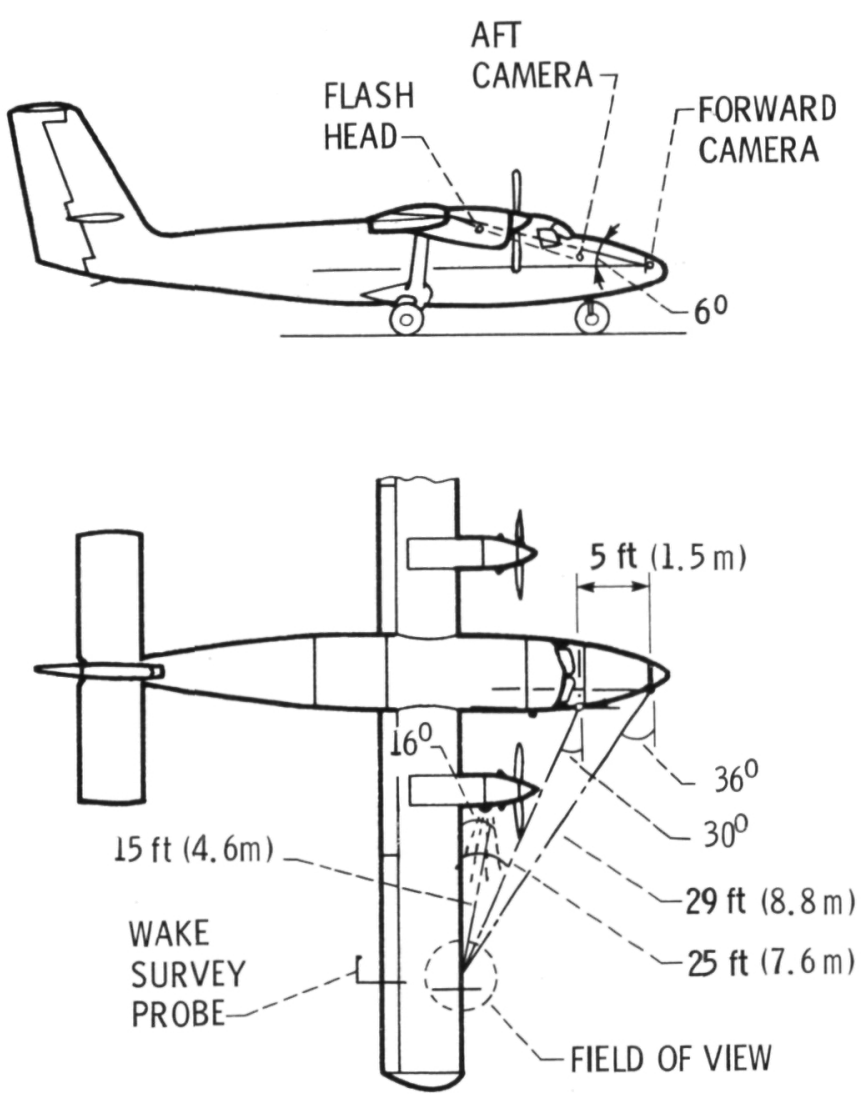

(a) Stereo camera system layout.

Figure 2. - Twin Otter stereo system geometry. 
ORIGINAL PACE IS

OF POOR QUALITY

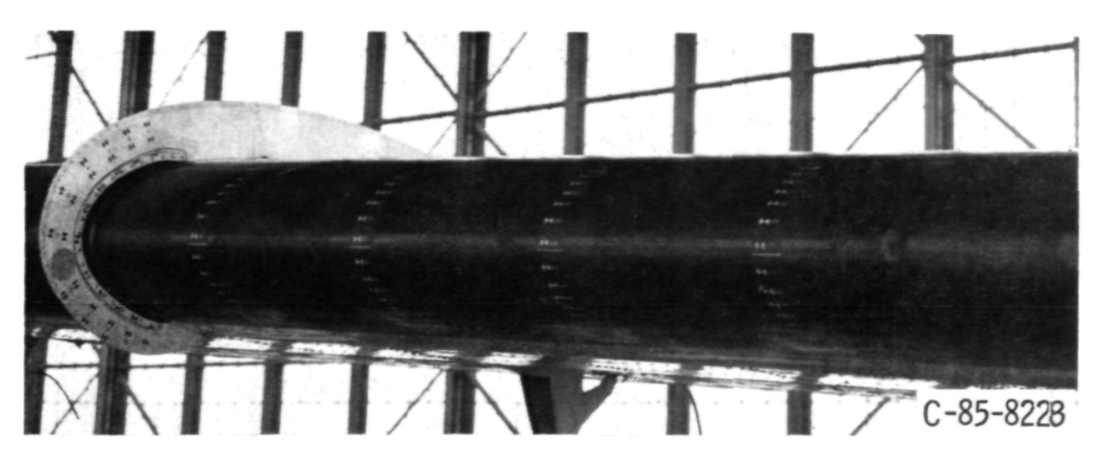

Figure 3. - Wing control point array.

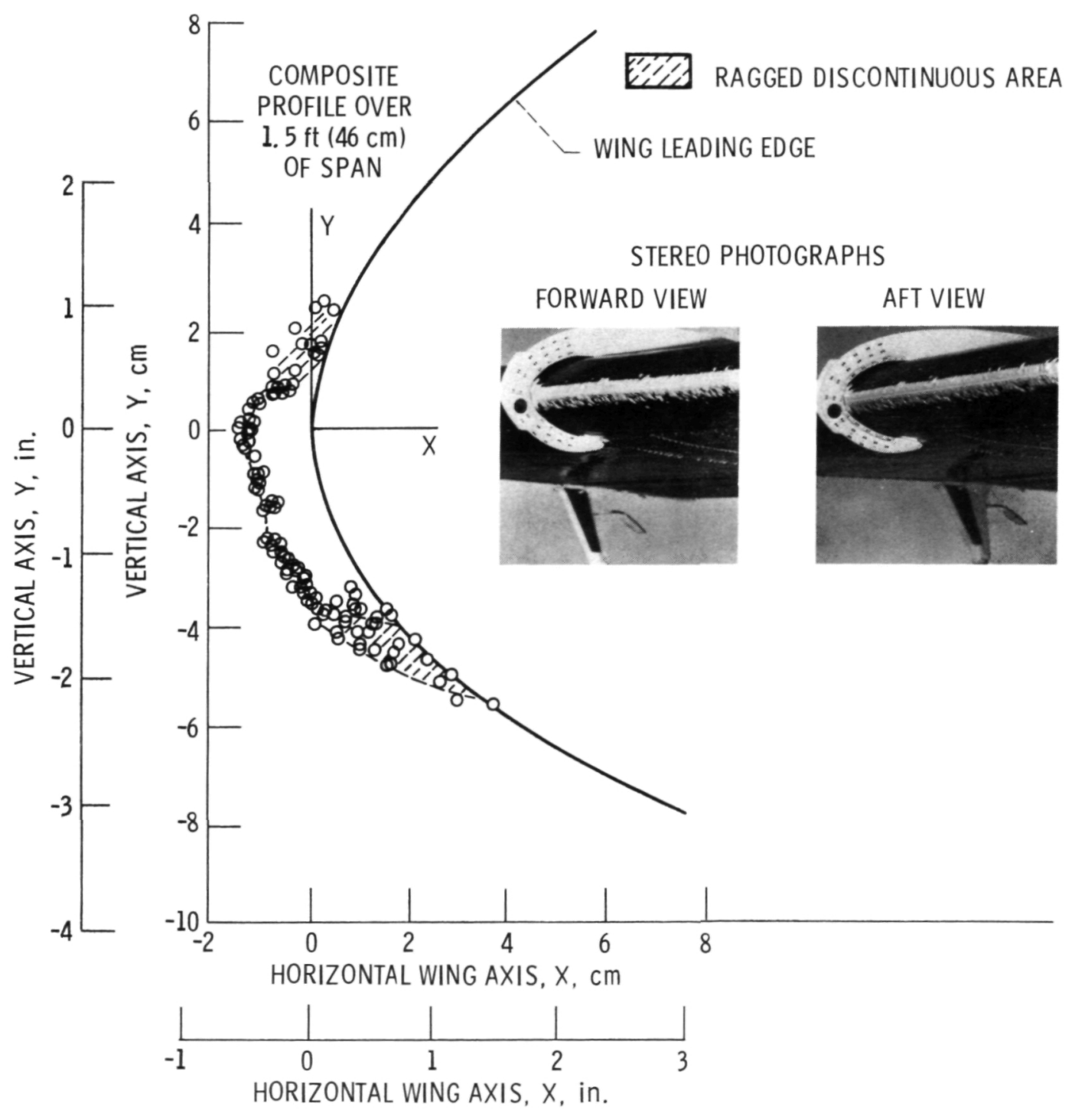

Figure 4. - Composite profile and stereo photographs of rime ice accretions. 


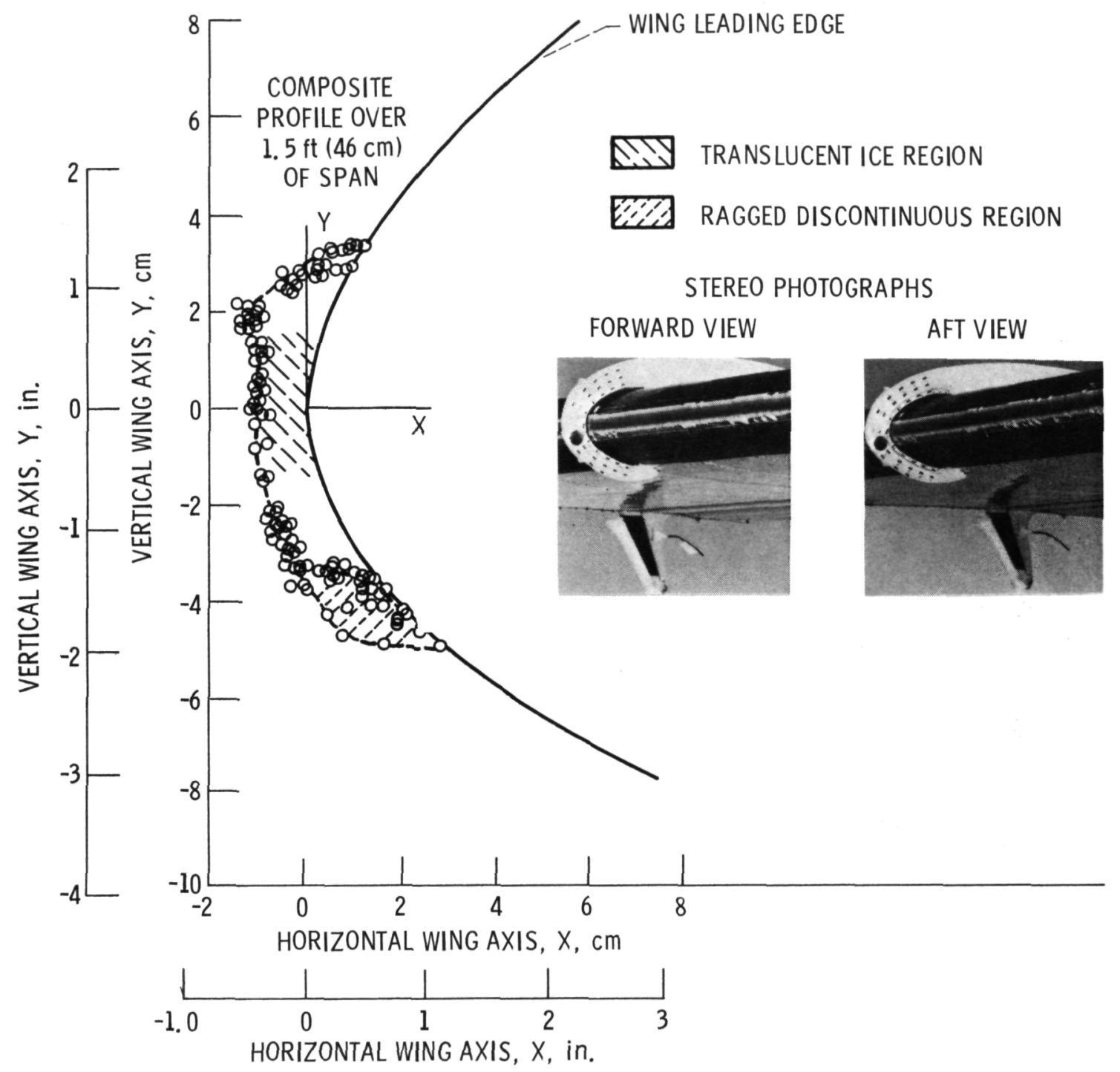

Figure 5. - Composite profile and stereo photographs of mixed ice. 


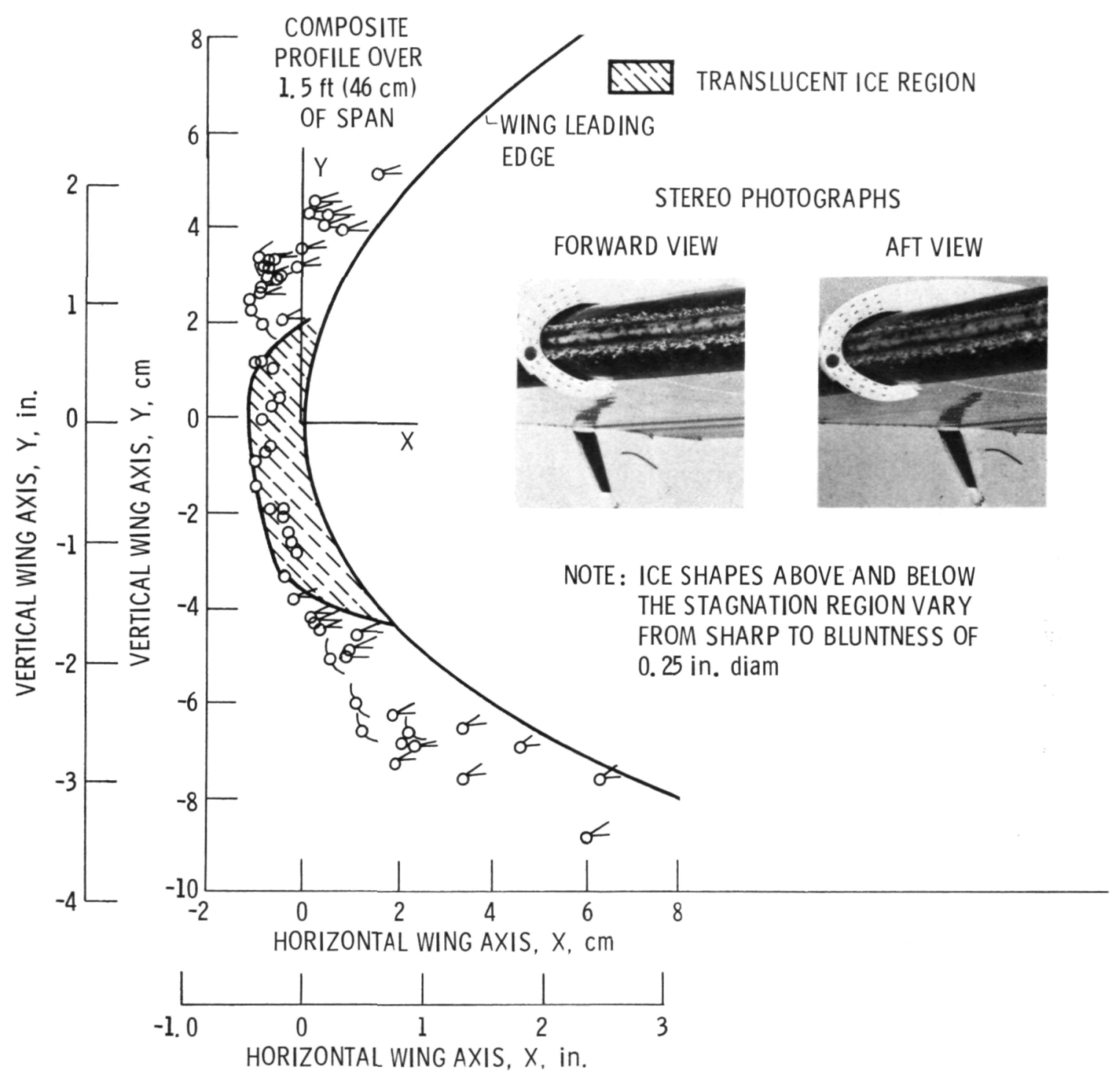

Figure 6. - Composite profile and stereo photographs of clear ice. 


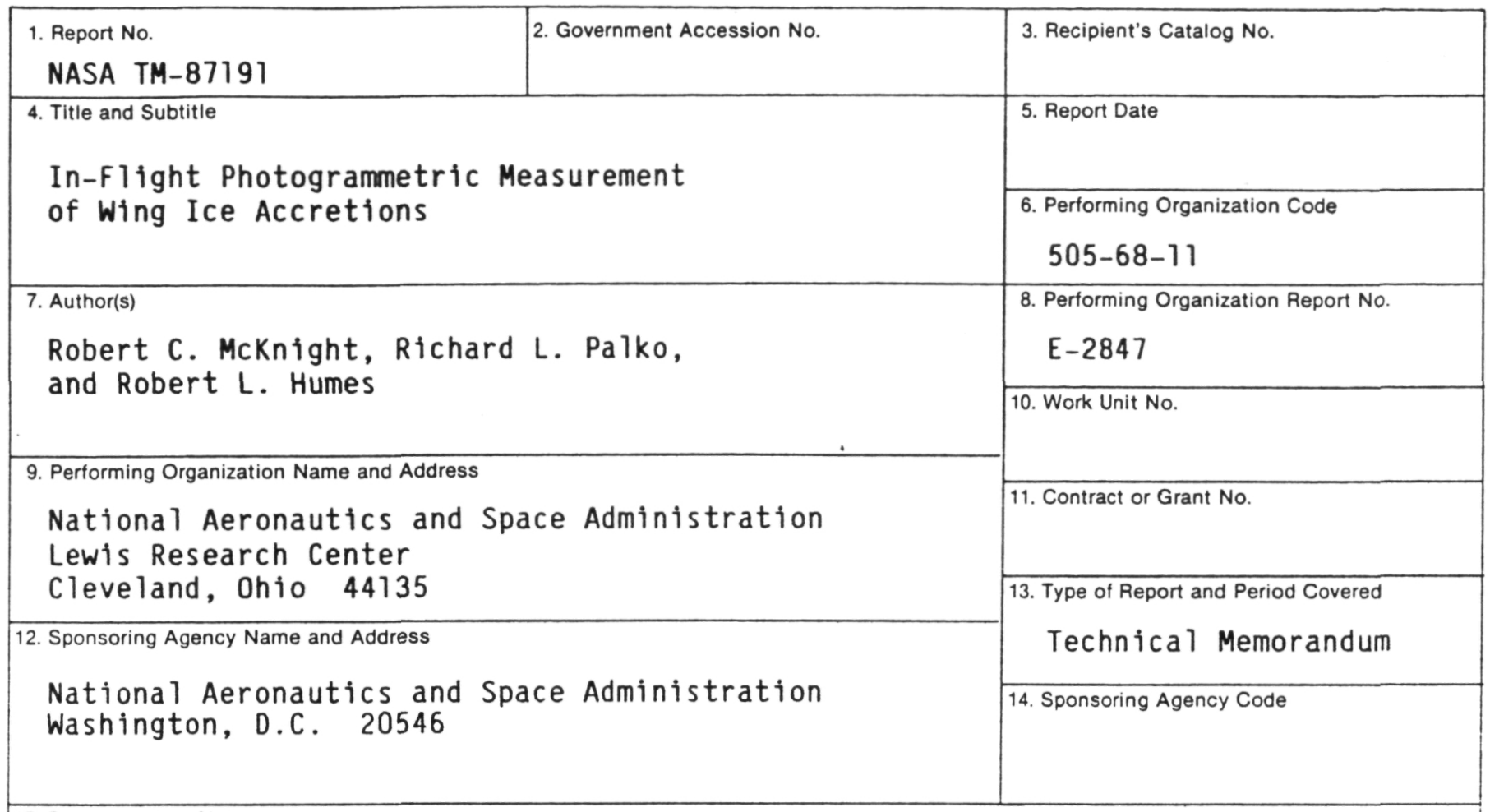

15. Supplementary Notes

Prepared for the Twenty-fourth Aerospace Sciences Meeting, sponsored by the American Institute of Aeronautics and Astronautics, Reno, Nevada, January 6-8, 1986. Robert C. Mcknight, NASA Lewis Research Center; Richard L. Palko and Robert L. Humes, Calspan Corporation, Arnold Air Force Station, Tennessee.

16. Abstract

A photographic instrumentation system was developed for the Lewis icing research aircraft to measure wing ice accretions during flight. The system generates stereo photographs of the accretions which are then photogrammetrically measured by the Air Force Arnold Engineering and Development Center. The measurements yield a survey of spatial coordinates of an accretion's surface to an accuracy of at least $+0.08 \mathrm{~cm}$. The accretions can then be matched to corresponding icing cloud and aerodynamic measurements. The system is being used to measure rime, mixed, and clear natural ice accretions.

17. Key Words (Suggested by Author(s))

Icing; flight test; Instrumentation; Stereo photogrammetry; Photogrammetry

\section{Distribution Statement}

Unclassified - unlimited

STAR Category 05 
National Aeronautics and

Space Administration

Lewis Research Center

Cleveland. Ohio 44135

Official Business

Penalty for Private Use $\$ 300$
SECOND CLASS MAIL

ADDRESS CORRECTION REQUESTED

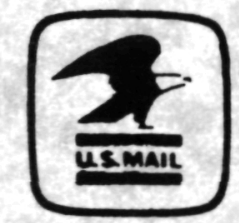

Postage and Fees Paid

National Aeronautics and

Space Administration

NASA-451 